\title{
Dietary glycaemic index, glycaemic load and endometrial and ovarian cancer risk: a systematic review and meta-analysis
}

\author{
HG Mulholland*,', LJ Murray', CR Cardwell' and MM Cantwell' \\ 'Cancer Epidemiology and Prevention Research Group, Centre for Clinical and Population Sciences, Queens University Belfast, Mulhouse Building, Royal \\ Victoria Hospital Site, Grosvenor Road, Belfast BTI 2 6BJ, Northern Ireland
}

Long-term consumption of a high glycaemic index (Gl) or glycaemic load (GL) diet may lead to chronic hyperinsulinaemia, which is a potential risk factor for cancer. To date, many studies have examined the association between $\mathrm{Gl}, \mathrm{GL}$ and cancer risk, although results have been inconsistent, therefore our objective was to conduct a systematic review of the literature. Medline and Embase were systematically searched using terms for Gl, GL and cancer to identify studies published before December 2007. Random effects metaanalyses were performed for endometrial cancer, combining maximally adjusted results that compared risk for those in the highest versus the lowest category of intake. Separate analysis examined risk by body mass index categories. Five studies examining Gl and/or GL intake and endometrial cancer risk were identified. Pooled effect estimates for endometrial cancer showed an increased risk for high GL consumers (RR I.20; 95\% Cl: 1.06-1.37), further elevated in obese women (RR I.54; 95\% Cl: 1.18-2.03). No significant associations were observed for Gl. Only two studies examined ovarian cancer and therefore no meta-analysis was performed, but results indicate positive associations for GL also. A high GL, but not a high $\mathrm{Gl}$, diet is positively associated with the risk of endometrial cancer, particularly among obese women.

British Journal of Cancer (2008) 99, 434-44I. doi:I0.1038/sj.bjc.6604496 www.bjcancer.com

(c) 2008 Cancer Research UK

Keywords: glycaemic index; glycaemic load; endometrial cancer; ovarian cancer; meta-analysis

Ovarian and endometrial cancers are currently ranked 7th and 8th of the most common female cancers worldwide, and typically occur in developed countries (WCRF/AICR, 2007). Established risk factors for both cancers include nulliparity and a long lifetime exposure to oestrogen, that is for those who experience early menarche and late menopause, whereas oral contraceptives are known to be protective (Rieck and Fiander, 2006). A high body mass index (BMI) has also been related to ovarian and endometrial cancer risk (Olsen et al, 2007; WCRF/AICR, 2007), and risk of the latter cancer can be exacerbated by polycystic ovarian syndrome in overweight or obese women (Furberg and Thune, 2003). Recently, it has been suggested that a moderately high carbohydrate, low glycaemic index (GI) diet may prevent insulin resistance and polycystic ovarian syndrome in women (Marsh and Brand-Miller, 2005).

Dietary GI is a method of classifying carbohydrate quality that ranks foods according to their effect on the 2-h postprandial blood glucose response (Jenkins et al, 1981). Food GI calculations are usually based on portions containing $50 \mathrm{~g}$ of carbohydrate however an individual's blood glucose, and hence insulin response, varies after consuming differing amounts of carbohydrates. This led to the introduction of the glycaemic load (GL) concept which accounts for the GI and total carbohydrate content of a food and

*Correspondence: HG Mulholland; E-mail hmulholland04@qub.ac.uk Received 22 February 2008; revised 31 May 2008; accepted 10 June 2008 is therefore considered a measure of carbohydrate quality and quantity (Salmeron et al, 1997).

Long-term consumption of a high GI or GL diet may lead to chronic hyperinsulinaemia, which has been shown to lower insulin-like growth factor binding protein (IGFBP) concentrations, thereby increasing insulin-like growth factor-1 (IGF-1) levels (Augustin et al, 2002). Increased IGF-1 bioactivity inhibits apoptosis, stimulates cell proliferation and sex steroid synthesis and inhibits sex-hormone binding globulin synthesis, all of which could be implicated in the development of endometrial and ovarian cancer (Kaaks et al, 2002; Lukanova and Kaaks, 2005).

Consuming a low GI diet may also be beneficial in avoiding weight gain and obesity (Brand-Miller et al, 2002), which is a contributing factor in the development of hyperinsulinaemia and excess oestrogen synthesis (Augustin et al, 2002). In turn, hyperinsulinaemia, together with boosted plasma IGF-1 levels, are thought to contribute to ovarian hyperandrogenism and a subsequent reduction in endogenous progesterone production, and it has been hypothesised that endometrial cancer risk is increased in women whose oestrogen levels are insufficiently counterbalanced by progesterone (Kaaks and Lukanova, 2001).

The epidemic of obesity, coupled with consumption of high GI or GL diets, are typically associated with developed countries, where the majority of ovarian and endometrial cancers are diagnosed (WCRF/AICR, 2007). In view of the biologically plausible mechanisms suggested above, it could be speculated that dietary GI and GL are associated with endometrial and ovarian cancer development and that BMI is a potential mediator of the 
effect. To date, studies that have examined the association between GI and GL intake and endometrial or ovarian cancer risk have produced inconsistent results. A systematic review of the literature would therefore be beneficial in order to create evidence-based guidelines for public health.

The aim of the overall systematic review was to establish whether dietary GI and GL are associated with risk of cancer, and in this case, specifically endometrial and ovarian cancer and to examine if risk varies by BMI.

\section{MATERIALS AND METHODS}

\section{Study selection}

Literature searches were conducted using Ovid Medline (US National Library of Medicine, Bethesda, MD, USA), Medline InProcess, Embase (Reed Elsevier PLC, Amsterdam, The Netherlands). The search strategy used medical subject heading (MeSH) terms and keywords: glyc(a)emic index, glyc(a)emic load, blood glucose, blood sugar(s) combined with diet, nutrition, dietary carbohydrate(s), carbohydrate(s), dietary fibre/fibre, fibre/fibre, dietary sugar(s), dietary sucrose and cancer, neoplasm(s), neoplasia, adenoma, adenocarcinoma or carcinoma. Searches were limited to studies conducted on humans published before December 2007. Review publication types were removed but no language restriction was specified. The identified articles were independently screened by two reviewers (HGM and MMC) to determine whether they met the inclusion criteria. To be included, studies with endometrial or ovarian cancer as an outcome had to have measured diet, and subsequently GI and/or GL in participants. The reviewers initially screened abstracts to remove obviously irrelevant articles, and then the full text articles. Discrepancies were resolved by discussion. Finally, the reference lists of all included articles were examined.

\section{Data extraction}

Data extraction was conducted independently by two reviewers (HGM and MMC) using piloted forms to record detailed information on the study design, population characteristics, dietary assessment methods used, confounders measured and, finally, the results. Where essential information was missing, authors were contacted personally. The reviewers applied the Newcastle-Ottawa Quality Assessment Scale (http://www.lri.ca) to all studies to consider factors such as selection of participants, comparability of studies, follow-up and ascertainment of exposure and outcome.

\section{Statistical analysis}

The association between cancer risk and GI or GL intake was summarised by comparing the risk of cancer in the highest reported category of GI (GL) intake to the lowest reported category. Adjusted relative risk estimates (RRs) and their corresponding standard errors were extracted from published reports for each study. The RRs extracted referred to the top quartile or quintile of intake compared with the lowest category of intake. In case-control studies, adjusted odds ratios (ORs) were used, and in cohort studies with variable follow-up: time adjusted hazard rate ratios (HRs) were used, although in some studies these were reported as RRs. Odds ratios and HRs should approximate RRs as endometrial and ovarian cancers are rare (Symons and Moore, 2002). Random effects models were used to calculate pooled RRs, and the $I^{2}$ statistic (Higgins et al, 2003) was calculated to quantify the degree of heterogeneity between studies. Random effects models were deemed more appropriate than fixed effects models because it was anticipated that there would be study heterogeneity due to their observational nature. Study-specific weights in the random effects model were calculated and scaled to percentages. Publication and selection bias were investigated by checking for asymmetry in the funnel plots of the study RRs against the standard error of the logarithm of the RRs (Sterne and Egger, 2001). The analysis was stratified by BMI, where this information was provided and separate analyses were undertaken for cohort and case-control studies. No meta-analysis was conducted on ovarian cancer because of the small number of studies published. Statistical analysis was conducted using Intercooled STATA (version 9.2, StataCorp 2005, College Station, TX, USA).

\section{RESULTS}

The search strategy results are shown in Figure 1. Five articles that were identified investigated endometrial cancer (Folsom et al, 2003; Augustin et al, 2003a; Silvera et al, 2005; Larsson et al, 2007; Cust et al, 2007a) and two that investigated ovarian cancer (Augustin et al, 2003b; Silvera et al, 2007); the characteristics of these studies are described in Table 1.

All studies principally employed either self-reported or interviewer-administrated validated Food Frequency Questionnaires (FFQs). Glycaemic index/GL values were primarily sourced from International Tables (Foster-Powell and Miller, 1995; Foster-Powell et al, 2002; Henry et al, 2005; University of Sydney website), with some studies supplementing these with local sources (Augustin et al, 2003b). All studies were conducted in Europe or North America. Many potential confounders were adjusted for in individual publications but these were inconsistent between studies (Table 1). All adjusted for age and energy intake, whereas adjustments for hormonal use, reproductive factors, menstrual history, physical activity and other dietary variables including alcohol intake varied between studies.

\section{Endometrial cancer}

Prospective cohorts accounted for four of the five studies identified that examined endometrial cancer risk, all of which incorporated adequate follow-up lengths, whereas the remaining study was a hospital-based case-control study. Cohort studies scored more highly on the quality scale compared with the casecontrol study (Table 1). In all studies, cases were identified by microscopic verification, linkage to cancer registries or self-report and women who had undergone a hysterectomy were excluded.

The association between endometrial cancer and GI intake for all five studies is shown in Figure 2. The combined adjusted RR of endometrial cancer in the highest reported category of GI intake

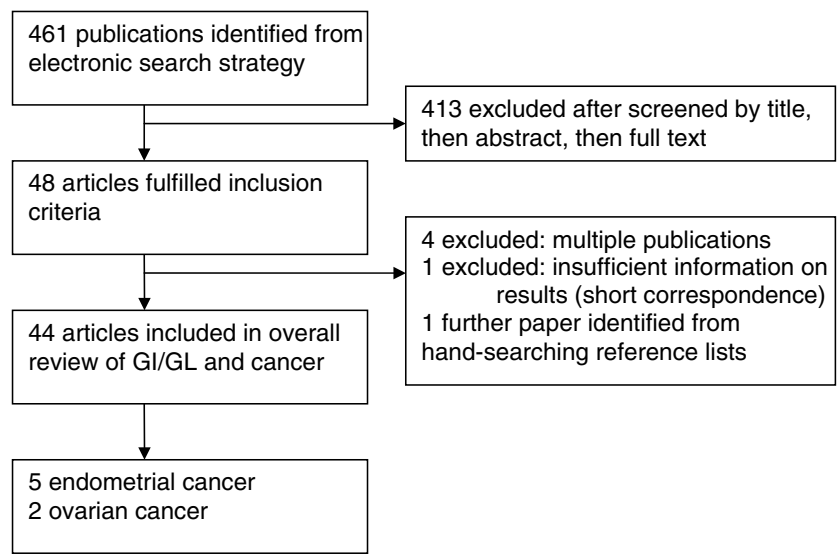

Figure I A flow diagram of study selection for $G / / G L$ and endometrial and ovarian cancer risk 
Table I Characteristics of studies included in systematic review of dietary glycaemic index, glycaemic load and risk of endometrial and ovarian cancer

\begin{tabular}{|c|c|c|c|c|c|c|c|c|c|c|c|c|c|c|c|c|c|c|c|c|}
\hline \multirow{2}{*}{$\begin{array}{l}\text { Study-year- } \\
\text { location }\end{array}$} & \multirow{2}{*}{$\begin{array}{c}\text { Study } \\
\text { design } \\
\text { (mean } \\
\text { follow-up) }\end{array}$} & \multirow{2}{*}{ Cases } & \multirow{2}{*}{$\begin{array}{l}\text { Controls/ } \\
\text { cohort } \\
\text { size }\end{array}$} & \multirow{2}{*}{$\begin{array}{l}\text { Diet } \\
\text { assessment }\end{array}$} & \multirow{2}{*}{$\begin{array}{l}\text { Quality } \\
\text { scale } \\
\text { score }\end{array}$} & \multirow[b]{2}{*}{$\begin{array}{l}\text { Median GI } \\
\text { (IQ range) }\end{array}$} & \multirow[b]{2}{*}{$\begin{array}{l}\text { Median GL } \\
\text { (IQ range) }\end{array}$} & \multicolumn{13}{|c|}{ Adjusted confounders } \\
\hline & & & & & & & & Age & BMI & Energy & Hormon. & Reprod. & Menstr. & Smoking & PA & Education & Alcohol & Fibre & Diabetes & Height \\
\hline \multicolumn{21}{|l|}{ Endometrial } \\
\hline $\begin{array}{l}\text { Cust et al } \\
\text { (2007a) } \\
\text { Europe }\end{array}$ & $\begin{array}{l}\text { Prospective } \\
\text { cohort (6.4 } \\
\text { years) }\end{array}$ & 710 & 288428 & $\begin{array}{l}\text { Self-reported/ } \\
\text { interviewed } \\
\text { FFQ and } \\
24-\mathrm{h} \text { recall }\end{array}$ & 9/9 & $56(53-58)$ & $117(94-144)$ & $r$ & $r$ & $r$ & \# & \# & \# & $\boldsymbol{r}$ & $r$ & \# & & & \# & $r$ \\
\hline $\begin{array}{l}\text { Larsson et al } \\
(2007) \\
\text { Sweden }\end{array}$ & $\begin{array}{l}\text { Prospective } \\
\text { cohort } \\
\text { (15.6 years) }\end{array}$ & 608 & 66651 & $\begin{array}{l}\text { Self-reported } \\
\text { 67-tem FFQ, } \\
\text { 96-tem FFQ }\end{array}$ & 9/9 & $80(74-86)$ & $181(155-210)$ & $\boldsymbol{r}$ & $r$ & $r$ & $\boldsymbol{r}$ & $r$ & $r$ & \# & \# & $\boldsymbol{\nu}$ & & & \# & \\
\hline $\begin{array}{l}\text { Silvera et al } \\
\text { (2005) } \\
\text { Canada }\end{array}$ & $\begin{array}{l}\text { Prospective } \\
\text { cohort } \\
\text { (16.4 years) }\end{array}$ & 426 & 34391 & $\begin{array}{l}\text { Self-reported } \\
\text { 86-item FFQ }\end{array}$ & 9/9 & $73(67-77)$ & $148(125-169)$ & $\nu$ & $r$ & $r$ & $\boldsymbol{r}$ & $r$ & $r$ & $\boldsymbol{r}$ & $r$ & & $r$ & & & \\
\hline $\begin{array}{l}\text { Folsom et al } \\
\text { (2003) } \\
\text { United States }\end{array}$ & $\begin{array}{l}\text { Prospective } \\
\text { cohort }(-)^{a}\end{array}$ & 415 & 23335 & $\begin{array}{l}\text { Self-reported } \\
\text { 126-item FFQ }\end{array}$ & 9/9 & $85(81-89)$ & $170(147-193)$ & $\nu$ & $r$ & $r$ & $r$ & & $r$ & $r$ & & & $r$ & & $\boldsymbol{r}$ & \\
\hline $\begin{array}{l}\text { Augustin et al } \\
(2003 a) \\
\text { Switzerland/titaly }\end{array}$ & $\begin{array}{l}\text { Hospital- } \\
\text { based case- } \\
\text { control }\end{array}$ & 410 & 753 & $\begin{array}{l}\text { Interviewed } \\
\text { 37-item FFQ }\end{array}$ & 6/9 & $82^{1} 74^{2}(70-88)$ & $143^{1} 112^{2}(108-214)$ & $\boldsymbol{r}$ & レ & $\nu$ & $r$ & & & & & $\boldsymbol{r}$ & & & $\nu$ & \\
\hline \multicolumn{21}{|l|}{ Ovarian } \\
\hline $\begin{array}{l}\text { Silvera et al } \\
\text { (2007) } \\
\text { Canada }\end{array}$ & $\begin{array}{l}\text { Prospective } \\
\text { cohort } \\
\text { (16.4 years) }\end{array}$ & 264 & 48776 & $\begin{array}{l}\text { Self-reported } \\
\text { 86-item FFQ }\end{array}$ & 9/9 & $77(63-92)$ & $148(125-169)$ & $\boldsymbol{r}$ & $\boldsymbol{r}$ & $\nu$ & $\boldsymbol{r}$ & $\boldsymbol{r}$ & $\boldsymbol{r}$ & & $\boldsymbol{r}$ & & $r$ & $r$ & & \\
\hline $\begin{array}{l}\text { Augustin et al } \\
(2003 b) \\
\text { Italy }\end{array}$ & $\begin{array}{l}\text { Hospital- } \\
\text { based case- } \\
\text { control }\end{array}$ & 1031 & 2411 & $\begin{array}{l}\text { Interviewed } \\
\text { 78-item FFQ }\end{array}$ & 6/9 & $74(70-78)$ & $185(147-234)$ & $\boldsymbol{r}$ & & $r$ & $r$ & $r$ & $r$ & & $r$ & $r$ & $r$ & $r$ & $r$ & \\
\hline
\end{tabular}

$\overline{F F Q}=$ Food Frequency Questionnaire; Gl = glycaemic index; GL = glycaemic load; IQ = Inter-quartile. Adjusted confounders: age; BMI = body mass index; Energy = energy intake; Hormon. = hormone replacement therapy/oral contraceptive use; Reprod. = reproductive factors, e.g., parity, age at first birth; Menstr.= menstrual history, e.g., age at menarche or menopause, menopausal status; Smoking; PA = physical activity; Education; Alcohol intake; Fibre = Fibre intake; Diabetes $=$ History of diabetes. ${ }^{\# I n d i c a t e s ~ p o t e n t i a l ~ c o n f o u n d e r s ~ t h a t ~ w e r e ~ t e s t e d ~ b u t ~ n o t ~ i n c l u d e d ~ i n ~ t h e ~ f i n a l ~ m o d e l . ~}{ }^{2}$ Total follow-up length 304558 women-years. "Values from Swiss centre, ${ }^{2}$ Values from Italian centre. 


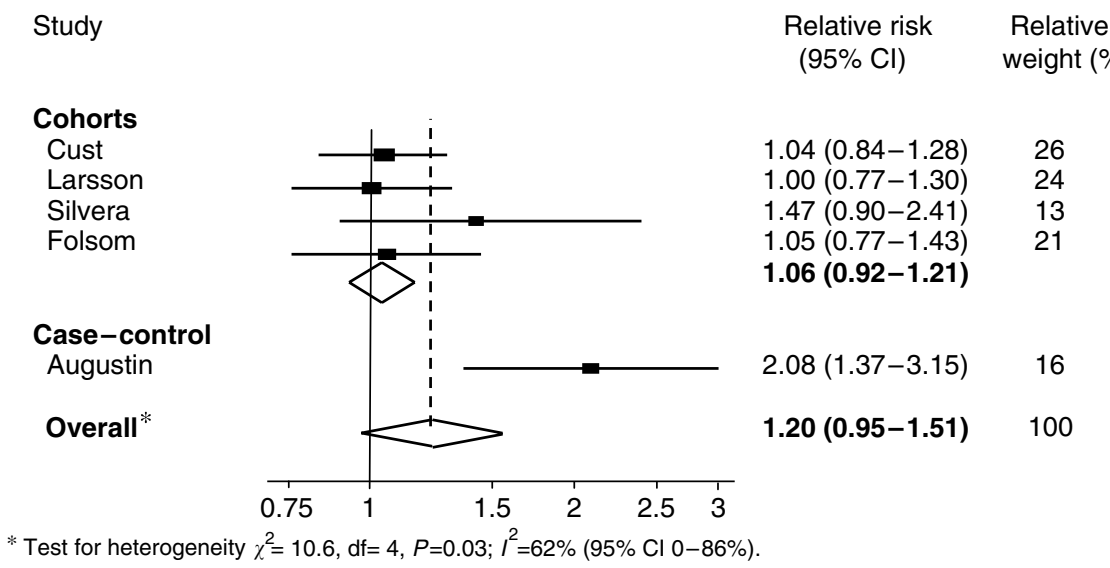

Figure 2 Meta-analysis of $\mathrm{Gl}$ and endometrial cancer risk.

Study

Cohorts
Cust
Larsson
Silvera
Folsom

Case-control Augustin

Overall* Relative risk
Relative weight $(\%)$ $\begin{array}{ll}1.15(0.94-1.41) & 24 \\ 1.15(0.88-1.51) & 21 \\ 1.36(1.01-1.84) & 20 \\ 1.24(0.90-1.72) & 19\end{array}$

$1.20(1.06-1.37)$

$2.74(1.79-4.19)$

16 $1.38(1.08-1.77) \quad 100$

* Test for heterogeneity $\chi^{2}=14.2, \mathrm{df}=4, P<0.01 ; I^{2}=72 \%(95 \% \mathrm{Cl} 29-89 \%)$.

Figure 3 Meta-analysis of $G L$ and endometrial cancer risk.

compared with the lowest reported GI category was 1.20 (95\% CI: $0.95-1.51)$; however, there was evidence of statistical heterogeneity $\left(I^{2}=62 \%, P=0.03\right)$. The statistical heterogeneity was markedly reduced $\left(I^{2}=0 \%, P=0.69\right)$ when only the four cohort studies were included in the analysis. There was little evidence of an association between GI and endometrial cancer in these studies (RR 1.06; 95\% CI: $0.92-1.21$ ).

The association between endometrial cancer risk and GL intake for the five studies is shown in Figure 3. The combined adjusted RR of endometrial cancer in the highest reported category of GL intake compared with the lowest reported category of GL intake was 1.38 (95\% CI: $1.08-1.77)$, but there was also evidence of marked heterogeneity $\left(I^{2}=72 \%, P<0.01\right)$. Again, after the removal of the case-control study, this heterogeneity was markedly reduced $\left(I^{2}=0 \%, P=0.80\right)$. The combined adjusted RR for the four remaining cohort studies was still statistically significant showing a $20 \%$ increased risk for endometrial cancer in women consuming a high GL diet (RR 1.20; 95\% CI: 1.06-1.37). The European Prospective Investigation into Cancer and Nutrition (EPIC) study also reported results of GI and GL intake as continuous variables and showed an elevated risk of endometrial cancer of 1.40 (95\% CI: $0.99-1.99)$ per $50 \mathrm{Uday}^{-1}$ increments in GL. There was little evidence of the presence of publication bias from examining funnel plots for GI or GL and for endometrial cancer risk.

The association between GL and endometrial cancer after stratification by BMI is shown in Figure 4. Additional information by BMI stratification was sought from Cust et al (2007a), as this study had indicated that the analysis had been conducted but not published. Stratified analysis in the case-control study was only shown for GI intake and additional information for GL was not obtained due to variation in BMI cutoffs. There was little evidence of an association between GL and endometrial cancer risk in the normal weight women (RR 1.05; 95\% CI: 0.86-1.28), some evidence of increased risk in the overweight group (RR 1.27; 95\% CI: $0.99-1.65)$ and strong evidence of a positive association in obese women (RR 1.54; 95\% CI: 1.18-2.03). There was little evidence of heterogeneity between studies in the analysis stratified by BMI. No significant associations were observed when GI and endometrial cancer risk were investigated by BMI category, with RRs of 1.03 (95\% CI: $0.81-1.31), 1.42$ (95\% CI: 0.95-2.11) and 1.01 (95\% CI: $0.71-1.43$ ) detected for normal weight, overweight and obese women, respectively.

Stratified analyses were performed according to other variables; however, too few studies did so to enable robust investigation of these by meta-analysis. Conflicting results indicated that the association between GL and endometrial cancer risk may be influenced by menopausal status (Silvera et al, 2005; Cust et al, 2007a), hormone replacement therapy (HRT) use (Augustin et al, 2003a; Folsom et al, 2003; Silvera et al, 2005), physical activity levels (Silvera et al, 2005; Larsson et al, 2007) or diabetes history (Folsom et al, 2003).

\section{Ovarian cancer}

One prospective cohort and one large case-control study of GI and GL intake and ovarian cancer risk have been conducted to 


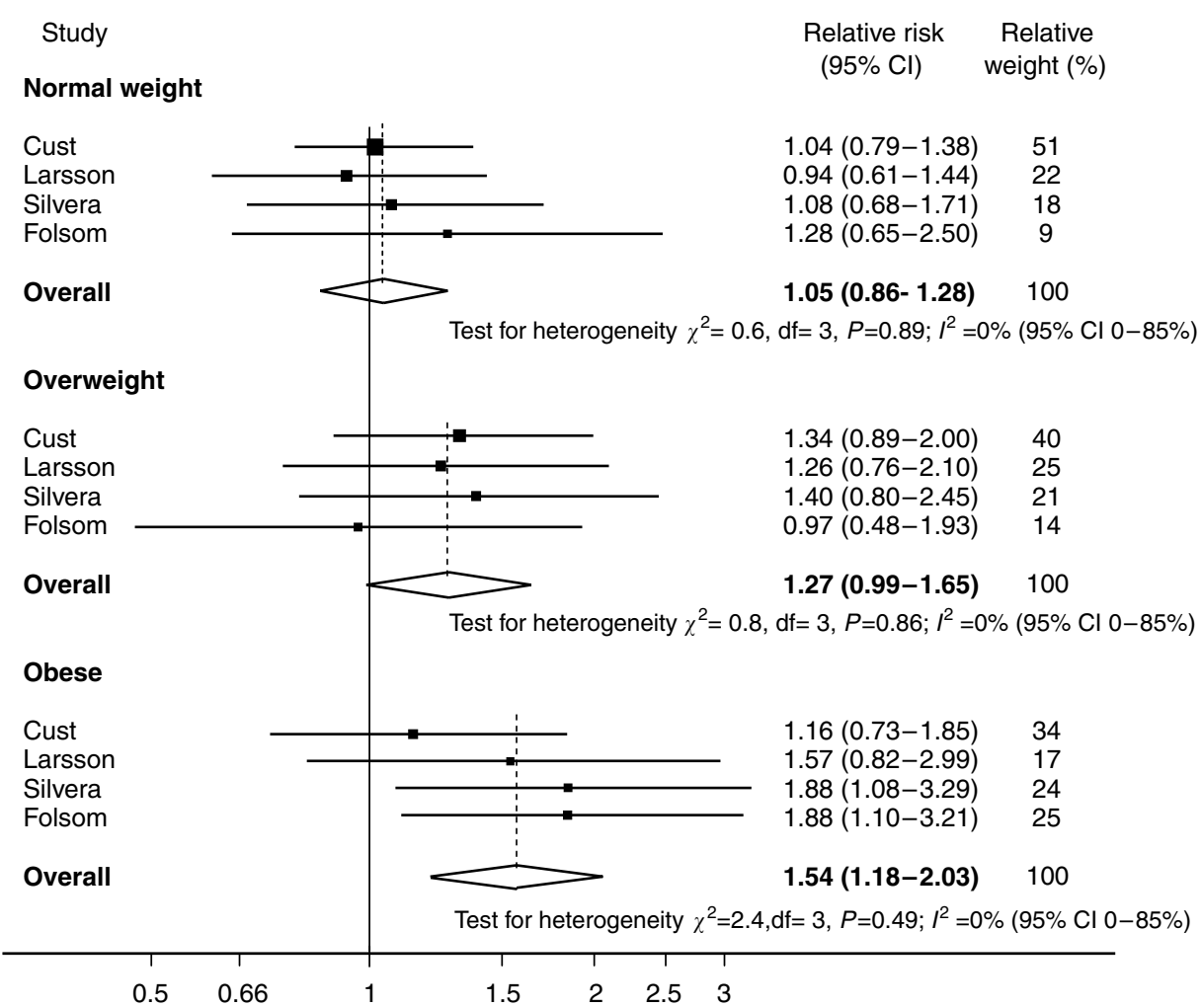

Figure 4 Meta-analysis of $\mathrm{GL}$ and endometrial cancer risk by BMl categories: normal weight $\left(\mathrm{BMl}<25 \mathrm{~kg} / \mathrm{m}^{2}\right)$, overweight (BMl $\geqslant 25$ and $\left.<30 \mathrm{~kg} / \mathrm{m}^{2}\right)$ and obese $\left(\mathrm{BMI} \geqslant 30 \mathrm{~kg} / \mathrm{m}^{2}\right)$.

date, with the latter study scoring slightly lower on the quality scale (Table 1). The cohort recruited women as part of the Canadian National Breast Screening programme, identifying cases by record linkage to national cancer and mortality databases. Although the Italian case-control study recruited hospital-based controls who may not reflect the general population, cases were histologically confirmed and any controls with modified dietary habits were excluded. Notably, although the latter study failed to adjust for BMI in their main analyses (Table 1), subgroup analyses results were stratified by BMI in the original publication.

Both studies detected an increase in the risk of ovarian cancer in the highest reported GI category compared with the lowest, although only the case-control study detected this association as significant (OR 1.65; 95\% CI: 1.30-2.09). Stratified analyses within the latter study demonstrated stronger associations between GI and ovarian cancer risk in postmenopausal women (which was not observed in the cohort study), overweight women, non-diabetics, non-oral contraceptive users, parous women, alcohol consumers and women without a family history of breast and/or ovarian cancer. Highly significant increased risks were detected in both studies of ovarian cancer and a high GL diet in all women (HR 2.15 ; 95\% CI: $1.29-2.09$ and OR $1.65 ; 95 \%$ CI: $1.30-2.09$, respectively). Both studies acknowledged that the majority of cases identified were postmenopausal and associations tended to be stronger for postmenopausal compared with that for premenopausal women.

\section{DISCUSSION}

This is the first systematic review of the evidence to date on GI and GL intake and endometrial cancer risk in relation to BMI and provides evidence of a positive association between high GL diets and endometrial cancer risk but little evidence of an association for dietary GI intake. The finding that a high GL diet increases the risk of endometrial cancer compared with a low GL diet demonstrates the advantage of a meta-analysis because only one of the individual studies reported statistically significant results, although all studies showed associations in a positive direction. It should be noted that some individual studies had a relatively narrow range of GI and GL intakes, which could explain the lack of statistically significant results observed in these studies. In the cohort studies, comparing the highest versus the lowest category of GL intake corresponded to an approximate difference of $50 \mathrm{GL}$ units (Folsom et al, 2003; Silvera et al, 2005, 2007; Cust et al, 2007a; Larsson et al, 2007), whereas in the case-control studies this observed difference was approximately 100 units (Augustin et al, 2003a,b). This could partly explain the stronger association observed in the meta-analysis of endometrial cancer risk and GL when the case-control study was included.

We did not observe an association between dietary GI and endometrial cancer risk. This would suggest that endometrial cancer risk is related to the actual blood glucose, and hence insulin, demand induced by the consumption of normal portion sizes of carbohydrates rather than the standard $50 \mathrm{~g}$ used to calculate GI values. Despite this, GI is still an important contributor to the GL value of a food, and it would be preferable to advise individuals to consume a diet composed of low GI/ moderate total carbohydrate content as opposed to high GI/low total carbohydrate content to achieve a low dietary GL intake. There is a paucity of research examining the association between dietary factors and endometrial or ovarian cancer risk. Investigations of total carbohydrate or cereals have provided weak or null associations (Jain et al, 2000; Trichopoulou et al, 2000). Identifying a strong association for any modifiable dietary factor and endometrial or ovarian cancer is therefore extremely valuable. In addition, there is little evidence to suggest that a low GI diet may have any accompanying adverse effects, and thus advising women 
to consume a low GL diet would seem a reasonable approach (Colombani, 2004).

Previous reports have shown a linear dose-response relationship between BMI and endometrial cancer risk (Jain et al, 2000; Furberg and Thune, 2003; Schouten et al, 2004; Friedenreich et al, 2007). Our findings that a high GL diet increases the risk of endometrial cancer as BMI increases, suggests that BMI may be an effect modifier of the association between GL and endometrial cancer, and that high GL diets may exaggerate endometrial cancer risk in women who are more likely to be insulin resistant. Additionally, a recent meta-analysis of 16 studies demonstrated that diabetics have over twice the risk of developing endometrial cancer compared with that of non-diabetics (Friberg et al, 2007). Similar elevated risks of ovarian cancer incidence and mortality were observed in a large UK cohort of diabetics compared with the general population (Swerdlow et al, 2005). Consuming low GI carbohydrates has been associated with improved glycaemic control in diabetic patients compared with high GI diets in randomised controlled trials (Brand-Miller et al, 2003). Other subgroup analyses in the papers included in our review have suggested that the association between GL and endometrial cancer may be modified by diabetes, menopausal status, HRT use or physical activity (Augustin et al, 2003a; Folsom et al, 2003; Silvera et al, 2005; Cust et al, 2007a; Larsson et al, 2007). Unfortunately, we were unable to perform meta-analyses on the basis of HRT use, diabetes or physical activity as too few studies reported results by these stratifications, and therefore no conclusions can be drawn with respect to these variables.

Although the mechanisms are recognised to differ by cancer site, the IGF system is often reported as the proposed mediator between GI, and therefore potentially GL and cancer risk (Du et al, 2006). A validation study of the effect of GI on the insulin response did report an overall $70 \%$ reduced insulin response after consumption of a low GI food compared with a high GI food (Brand-Miller et al, 2005). However, alterations to IGF-1 and IGFBP-3 levels were minimal following the low GI food compared with the high GI food. Notably, this study was conducted in lean young subjects, so the application of these findings to obese people is currently unknown. Obese subjects are known to have elevated circulating IGF-1 levels as a result of overnutrition (Augustin et al, 2002), and it is therefore plausible that a high GL diet in people with a higher BMI has a more profound effect on IGF-1 levels. Unfortunately, studies that have investigated the association between the IGF system and endometrial and ovarian cancer risk have produced inconsistent findings (Lukanova et al, 2004; Peeters et al, 2007; Tworoger et al, 2007). Despite this, C-peptide, a marker of pancreatic insulin production, has repeatedly been shown to be directly related to endometrial cancer risk in well-designed studies (Lukanova et al, 2004; Cust et al, 2007b), suggesting a key role for hyperinsulinaemia. The majority of endometrial cancers are oestrogen-related (WCRF/AICR, 2007), therefore hyperinsulinaemia induced by a habitually high GL diet may explain the increased endometrial, and possibly ovarian, cancer risk by the 'unopposed oestrogen' hypothesis.

Oestrogen is a known mitogen, and overweight and obesity could increase endometrial and ovarian cancer risk due to ovarian hyperandrogenism (surplus ovarian androgen production), which is promoted by hyperinsulinaemia, resulting in a subsequent oestrogen excess derived from the aromatisation of androgens in adipose tissue (Kaaks et al, 2002). In postmenopausal women, the cessation of progesterone synthesis results in oestrogen concentrations being insufficiently counterbalanced, while in hyperinsulinaemic premenopausal women, absent ovulation and ensuing progesterone deficiency may also enhance the mitogenic potential of oestrogen (Kaaks and Lukanova, 2001; Kaaks et al, 2002). Others have recognised that insulin levels per se cannot explain the disparity in the observed risk between obesity and premenopausal and postmenopausal breast cancer risk, whereas oestrogen concentrations are well correlated (Key, 2001).

The precise mechanisms through which a high GL diet increases endometrial, and potentially ovarian, cancer risk needs to be clarified in further research that utilises independent biomarkers such as C-peptide or components of the IGF system, in addition to dietary exposure. The inclusion of biomarkers could help to overcome the limitations associated with dietary GI and GL evaluation. For example, GI and GL values apply only to single foods, so when composite meals are consumed the ability to predict insulinaemic responses from GI values has been questioned (Flint et al, 2004). Blood glucose and insulin concentrations can also be influenced by other dietary components such as protein and fats (Jenkins et al, 1984). Furthermore, the studies in our systematic review used a mixture of glucose and white bread reference values for GI and GL. The reproducibility of GI and GL values and their application to different population groups are often highlighted as important methodological issues (Feskens and $\mathrm{Du}, 2006$ ), and to our knowledge, the validity of combining GI and GL results from different populations is currently unknown.

Other limitations to individual study designs reported in this review include the possibility of recall bias in case-control studies, whereby cases recall their diet differently compared with healthy controls (Augustin et al, 2003a,b). Self-administered FFQs were used in all of the prospective cohorts, none of which were specifically designed for assessing GI or GL intake. Food Frequency Questionnaires are known to incorporate some dietary measurement error, especially among overweight or obese individuals but are the most convenient assessment tool available for large-scale studies (Black et al, 1993). The FFQ employed in one of the case-control studies was also relatively short, including only 37 items (Augustin et al, 2003a). Only two cohorts incorporated repeat dietary measures (Cust et al, 2007a; Larsson et al, 2007), one of which used a single 24-h recall in a stratified random sample of participants in addition to an FFQ (Cust et al, 2007a), whereas the other obtained dietary information using an FFQ at two different time points (Larsson et al, 2007). Despite potential dietary measurement error, it is unlikely that the women in these studies were aware of any potential link between dietary GI or GL and cancer at the time of participation, which ranged between the 1980 s and 1990s.

Our meta-analysis of GI and GL intake and endometrial cancer risk does have limitations. The overall results are based on only five studies, and only four studies are included in the analysis stratified by BMI. However, all studies incorporated a large number of cases, particularly the EPIC study, which is a multicentre investigation of the association between diet and cancer risk in 10 European countries. Potential confounders such as parity, hormonal use, age at menarche and age at menopause were not universally adjusted for, which is not ideal when combining results; however, age, energy intake and BMI were adjusted for in all studies. We only compared low GI (GL) intake with high GI (GL) intake in reported categorisations, which differed from study to study. It is also difficult to determine with certainty any effect of publication bias or heterogeneity in such a small sample of studies, as indicated by the wide confidence intervals shown in the $I^{2}$ test for heterogeneity. In addition, the possibility of residual confounding cannot be ruled out.

Future well-designed studies or consortium-based analyses with a large number of cases, and consequently, more power should be conducted, particularly for the examination of interactions in high-risk insulin-resistant population groups, that is overweight, obese and sedentary women, to confirm our results. Further research is required on the effects of a high GI or GL diet in ovarian cancer, as our systematic review included only two studies, both of which showed results similar to those seen for endometrial cancer risk. 
In conclusion, consuming a high GL diet is associated with an increased risk of endometrial cancer and risk is further increased in obese women. Dietary GI does not appear to be related to endometrial cancer risk. Further research is required on GI, GL and ovarian cancer risk.

\section{ACKNOWLEDGEMENTS}

We acknowledge Ms Alex Mcllroy for her assistance in developing the electronic search strategy used in the systematic review.

\section{REFERENCES}

Augustin LS, Franceschi S, Jenkins DJ, Kendall CW, La Vecchia C (2002) Glycemic index in chronic disease: a review. Eur J Clin Nutr 56: $1049-1071$

Augustin LS, Gallus S, Bosetti C, Levi F, Negri E, Franceschi S, Dal Maso L, Jenkins DJ, Kendall CW, La Vecchia C (2003a) Glycemic index and glycemic load in endometrial cancer. Int J Cancer 105: 404-407

Augustin LS, Polesel J, Bosetti C, Kendall CW, La Vecchia C, Parpinel M, Conti E, Montella M, Franceschi S, Jenkins DJ, Dal Maso L (2003b) Dietary glycemic index, glycemic load and ovarian cancer risk: a casecontrol study in Italy. Ann Oncol 14: $78-84$

Black AE, Prentice AM, Goldberg GR, Jebb SA, Bingham SA, Livingstone MB, Coward WA (1993) Measurements of total energy expenditure provide insights into the validity of dietary measurements of energy intake. J Am Diet Assoc 93: $572-579$

Brand-Miller J, Hayne S, Petocz P, Colagiuri S (2003) Low-glycemic index diets in the management of diabetes: a meta-analysis of randomized controlled trials. Diabetes Care 26: 2261-2267

Brand-Miller JC, Holt SH, Pawlak DB, McMillan J (2002) Glycemic index and obesity. Am J Clin Nutr 76: 281S-285S

Brand-Miller JC, Liu V, Petocz P, Baxter RC (2005) The glycemic index of foods influences postprandial insulin-like growth factor-binding protein responses in lean young subjects. Am J Clin Nutr 82: 350-354

Colombani PC (2004) Glycemic index and load-dynamic dietary guidelines in the context of diseases. Physiol Behav 83: 603-610

Cust AE, Allen NE, Rinaldi S, Dossus L, Friedenreich C, Olsen A, Tjonneland A, Overvad K, Clavel-Chapelon F, Boutron-Ruault MC Linseisen J, Chang-Claude J, Boeing $H$, Schulz $M$, Benetou V, Trichopoulou A, Trichopoulos D, Palli D, Berrino F, Tumino R, Mattiello A, Vineis P, Quiros JR, Agudo A, Sanchez MJ, Larranaga N, Navarro C, Ardanaz E, Bueno-de-Mesquita $\mathrm{HB}$, Peeters PH, van Gils $\mathrm{CH}$, Bingham S, Khaw KT, Key T, Slimani N, Riboli E, Kaaks R (2007a) Dietary carbohydrates, glycemic index, glycemic load, and endometrial cancer risk within the european prospective investigation into cancer and nutrition cohort. Am J Epidemiol 166: $912-923$

Cust AE, Slimani N, Kaaks R, van Bakel M, Biessy C, Ferrari P, Laville M, Tjonneland A, Olsen A, Overvad K, Lajous M, Clavel-Chapelon F, Boutron-Ruault MC, Linseisen J, Rohrmann S, Nothlings U, Boeing H, Palli D, Sieri S, Panico S, Tumino R, Sacerdote C, Skeie G, Engeset D, Gram IT, Quiros JR, Jakszyn P, Sanchez MJ, Larranaga N, Navarro C, Ardanaz E, Wirfalt E, Berglund G, Lundin E, Hallmans G, Bueno-deMesquita HB, Du H, Peeters PH, Bingham S, Khaw KT, Allen NE, Key TJ, Jenab M, Riboli E (2007b) Serum levels of C-peptide, IGFBP-1 and IGFBP-2 and endometrial cancer risk; results from the European prospective investigation into cancer and nutrition. Int J Cancer 120: 2656-2664

Du H, Van der ADL, Feskens EJ (2006) Dietary glycaemic index: a review of the physiological mechanisms and observed health impacts. Acta Cardiol 61: $383-397$

Feskens EJ, Du H (2006) Dietary glycaemic index from an epidemiological point of view. Int J Obes (Lond) 30(Suppl 3): S66-S71

Flint A, Moller BK, Raben A, Pedersen D, Tetens I, Holst JJ, Astrup A (2004) The use of glycaemic index tables to predict glycaemic index of composite breakfast meals. Br J Nutr 91: 979-989

Folsom AR, Demissie Z, Harnack L, Iowa Women's Health Study (2003) Glycemic index, glycemic load, and incidence of endometrial cancer: the Iowa Women's Health Study. Nutr Cancer 46: 119-124

Foster-Powell K, Holt SH, Brand-Miller JC (2002) International table of glycemic index and glycemic load values: 2002. Am J Clin Nutr 76: 5-56

Foster-Powell K, Miller JB (1995) International tables of glycemic index. Am J Clin Nutr 62: 871S-890S

Friberg E, Orsini N, Mantzoros CS, Wolk A (2007) Diabetes mellitus and risk of endometrial cancer: a meta-analysis. Diabetologia 50: 1365-1374

Friedenreich C, Cust A, Lahmann PH, Steindorf K, Boutron-Ruault MC, Clavel-Chapelon F, Mesrine S, Linseisen J, Rohrmann S, Boeing H,
Pischon T, Tjonneland A, Halkjaer J, Overvad K, Mendez M, Redondo ML, Garcia CM, Larranaga N, Tormo MJ, Gurrea AB, Bingham S, Khaw KT, Allen N, Key T, Trichopoulou A, Vasilopoulou E, Trichopoulos D, Pala V, Palli D, Tumino R, Mattiello A, Vineis P, Bueno-de-Mesquita HB, Peeters PH, Berglund G, Manjer J, Lundin E, Lukanova A, Slimani N, Jenab M, Kaaks R, Riboli E (2007) Anthropometric factors and risk of endometrial cancer: the European prospective investigation into cancer and nutrition. Cancer Causes Control 18: 399-413

Furberg AS, Thune I (2003) Metabolic abnormalities (hypertension, hyperglycemia and overweight), lifestyle (high energy intake and physical inactivity) and endometrial cancer risk in a Norwegian cohort. Int J Cancer 104: 669-676

Henry CJ, Lightowler HJ, Strik CM, Renton H, Hails S (2005) Glycaemic index and glycaemic load values of commercially available products in the UK. Br J Nutr 94: 922-930

Higgins JP, Thompson SG, Deeks JJ, Altman DG (2003) Measuring inconsistency in meta-analyses. BMJ 327: $557-560$

Jain MG, Rohan TE, Howe GR, Miller AB (2000) A cohort study of nutritional factors and endometrial cancer. Eur J Epidemiol 16: $899-905$

Jenkins DJ, Wolever TM, Jenkins AL, Josse RG, Wong GS (1984) The glycaemic response to carbohydrate foods. Lancet 2: 388-391

Jenkins DJ, Wolever TM, Taylor RH, Barker H, Fielden H, Baldwin JM, Bowling AC, Newman HC, Jenkins AL, Goff DV (1981) Glycemic index of foods: a physiological basis for carbohydrate exchange. Am J Clin Nutr 34: $362-366$

Kaaks R, Lukanova A (2001) Energy balance and cancer: the role of insulin and insulin-like growth factor-I. Proc Nutr Soc 60: $91-106$

Kaaks R, Lukanova A, Kurzer MS (2002) Obesity, endogenous hormones, and endometrial cancer risk: a synthetic review. Cancer Epidemiol Biomarkers Prev 11: $1531-1543$

Key TJ (2001) Glycemic index, hyperinsulinemia, and breast cancer risk. Ann Oncol 12: $1507-1509$

Larsson SC, Friberg E, Wolk A (2007) Carbohydrate intake, glycemic index and glycemic load in relation to risk of endometrial cancer: a prospective study of Swedish women. Int J Cancer 120: 1103-1107

Lukanova A, Kaaks R (2005) Endogenous hormones and ovarian cancer: epidemiology and current hypotheses. Cancer Epidemiol Biomarkers Prev 14: $98-107$

Lukanova A, Zeleniuch-Jacquotte A, Lundin E, Micheli A, Arslan AA, Rinaldi S, Muti P, Lenner P, Koenig KL, Biessy C, Krogh V, Riboli E, Shore RE, Stattin P, Berrino F, Hallmans G, Toniolo P, Kaaks R (2004) Prediagnostic levels of C-peptide, IGF-I, IGFBP -1, -2 and -3 and risk of endometrial cancer. Int J Cancer 108: 262-268

Marsh K, Brand-Miller J (2005) The optimal diet for women with polycystic ovary syndrome? Br J Nutr 94: 154-165

Olsen CM, Green AC, Whiteman DC, Sadeghi S, Kolahdooz F, Webb PM (2007) Obesity and the risk of epithelial ovarian cancer: a systematic review and meta-analysis. Eur J Cancer 43: 690-709

Peeters PH, Lukanova A, Allen N, Berrino F, Key T, Dossus L, Rinaldi S, van Gils CH, Bueno-de-Mesquita HB, Boeing H, Schulz M, Chang-Claude J, Linseisen J, Panico S, Sacerdote C, Palli D, Tumino R, Trichopoulou A, Trichopolos D, Bamia C, Larranaga N, Ardanaz E, Pera G, Quiros JR, Martinez-Garcia C, Navarro C, Bingham SA, Khaw KT, Clavel F, Tjonneland A, Olsen A, Overvad K, Tetsche MS, Lund E, Lundin E, Berglund G, Riboli E, Kaaks R (2007) Serum IGF-I, its major binding protein (IGFBP-3) and epithelial ovarian cancer risk: the European Prospective Investigation into Cancer and Nutrition (EPIC). Endocr Relat Cancer 14: 81 - 90

Rieck G, Fiander A (2006) The effect of lifestyle factors on gynaecological cancer. Best Pract Res Clin Obstet Gynaecol 20: 227-251

Salmeron J, Manson JE, Stampfer MJ, Colditz GA, Wing AL, Willett WC (1997) Dietary fiber, glycemic load, and risk of non-insulin-dependent diabetes mellitus in women. JAMA 277: $472-477$ 


\section{GI, GL and endometrial and ovarian cancer}

HG Mulholland et al

Schouten LJ, Goldbohm RA, van den Brandt PA (2004) Anthropometry, physical activity, and endometrial cancer risk: results from the Netherlands Cohort Study. J Natl Cancer Inst 96: 1635-1638

Silvera SA, Jain M, Howe GR, Miller AB, Rohan TE (2007) Glycaemic index, glycaemic load and ovarian cancer risk: a prospective cohort study. Public Health Nutr 10(10): 1076-1081

Silvera SA, Rohan TE, Jain M, Terry PD, Howe GR, Miller AB (2005) Glycaemic index, glycaemic load and risk of endometrial cancer: a prospective cohort study. Public Health Nutr 8: $912-919$

Sterne JA, Egger M (2001) Funnel plots for detecting bias in metaanalysis: guidelines on choice of axis. J Clin Epidemiol 54: 10461055

Swerdlow AJ, Laing SP, Qiao Z, Slater SD, Burden AC, Botha JL, Waugh NR, Morris AD, Gatling W, Gale EA, Patterson CC, Keen H (2005) Cancer incidence and mortality in patients with insulin-treated diabetes: a UK cohort study. Br J Cancer 92: 2070-2075

Symons MJ, Moore DT (2002) Hazard rate ratio and prospective epidemiological studies. J Clin Epidemiol 55: 893-899

Trichopoulou A, Lagiou P, Kuper H, Trichopoulos D (2000) Cancer and Mediterranean dietary traditions. Cancer Epidemiol Biomarkers Prev 9: $869-873$

Tworoger SS, Lee IM, Buring JE, Pollak MN, Hankinson SE (2007) Insulinlike growth factors and ovarian cancer risk: a nested case-control study in three cohorts. Cancer Epidemiol Biomarkers Prev 16: $1691-1695$

University of Sydney Glycaemic Index database; http://www.glycaemicindex.com World Cancer Research Fund/American Institute for Cancer Research (2007) Food, Nutrition, Physical Activity, and the Prevention of Cancer: a Global Perspective. AICR: Washington, DC 